\title{
Níveis de triptofano digestível em rações para suínos machos castrados de alto potencial genético para deposição de carne na carcaça dos 60 aos $95 \mathbf{~ k g}$
}

\section{Douglas Haese ${ }^{2}$, Juarez Lopes Donzele ${ }^{3}$, Rita Flávia Miranda de Oliveira ${ }^{3}$, Márvio Lobão Teixeira de Abreu ${ }^{4}$, Francisco Carlos de Oliveira Silva ${ }^{5}$, Alysson Saraiva ${ }^{6}$}

\author{
1 Parte da dissertação de Mestrado do primeiro autor. Projeto apoiado pela Ajinomoto Biolatina. \\ 2 Estudante de Doutorado em Zootecnia - UFV. \\ 3 DZO/UFV. \\ 4 DZO/UFPI. \\ 5 EPAMIG. \\ ${ }^{6}$ Mestrando em Zootecnia - UFV.
}

RESUMO - Foram utilizados 70 suínos machos castrados, híbridos comerciais de alto potencial genético para deposição de carne na carcaça (peso inicial de $60,0 \pm 1,34 \mathrm{~kg}$ e peso final de $95,00 \pm 0,97 \mathrm{~kg}$ ), para avaliar o efeito dos níveis de triptofano digestível sobre o desempenho e as características de carcaça. Adotou-se delineamento experimental de blocos ao acaso, com cinco tratamentos $(0,128 ; 0,136 ; 0,144 ; 0,152$ e $0,160 \%$ de triptofano digestível, correspondentes às relações de $16,17,18$, 19 e $20 \%$ de triptofano:lisina digestíveis), sete repetições e dois animais por unidade experimental. Os níveis de triptofano digestível não influenciaram o consumo de ração, o ganho de peso, a conversão alimentar, a espessura de toucinho e o rendimento de carne. O consumo de triptofano digestível aumentou linearmente com o aumento dos níveis de triptofano digestível na dieta. O nível de $0,128 \%$ de triptofano digestível, correspondente a uma relação triptofano:lisina digestíveis de $16 \%$, atendeu às exigências de suínos machos castrados de alto potencial genético para deposição de carne na carcaça dos 60 aos $95 \mathrm{~kg}$.

Palavras-chave: aminoácidos, características de carcaça, desempenho, terminação

\section{Dietary digestible tryptophan levels for barrows with of high genetic potential for lean deposition in the carcass from 60 to $95 \mathrm{~kg}$}

\begin{abstract}
Seventy commercial hybrid barrows with high genetic potential for lean deposition in the carcass averaging initial and final body weight of $60.0 \pm 1.34 \mathrm{~kg}$ and $95.0 \pm 0.97 \mathrm{~kg}$, respectively, were used to evaluate the effects of dietary digestible tryptophan levels on performance and carcass characteristics. The experiment was analyzed as a randomized experimental block design with five treatments $(0.128,0.136,0.144,0.152$, and $0.160 \%)$ of digestible tryptophan, that is correspondent to the digestible tryptophan:lysine ratios of 16,17, 18, 19 and 20\%, with seven replicates and two animals per experimental unit. No treatment effect on feed intake, weight gain, feed:gain ratio, backfat thickness and lean yield was observed. The digestible tryptophan intake linearly increased as dietary digestible tryptophan levels increased.The $0.128 \%$ digestible tryptophan level, that is correspondent to a $16 \%$ digestible tryptophan:lysine ratio, met the requirements of barrows with high genetic potential for lean deposition in the carcass from 60 to $95 \mathrm{~kg}$.
\end{abstract}

Key Words: amino acids, carcass characteristics, finishing, performance

\section{Introdução}

Na suinocultura atual, entre outros objetivos, destacam-se a otimização do desempenho e a obtenção de carcaças com maior quantidade de tecido magro. Para a viabilização desta moderna suinocultura, é essencial o estabelecimento de corretos níveis aminoacídicos na ração.

O melhor balanceamento dos aminoácidos das rações pode ser obtido utilizando-se conceito da proteína ideal, entendido como o balanço entre os aminoácidos da dieta capaz de suprir as exigências de todos os aminoácidos necessários à perfeita manutenção e ao crescimento da espécie. Neste conceito, a lisina tem sido utilizada como referência no estabelecimento da exigência dos demais aminoácidos, expressos como relação ou porcentagem do valor de lisina.

A utilização de híbridos comerciais e a disponibilização comercial de grande quantidade de aminoácidos sintéticos, como lisina, metionina, treonina e triptofano, têm proporcionado aos nutricionistas a possibilidade de formular rações ajustadas segundo as exigências específicas para 
cada situação, otimizando o potencial de desempenho e as características de carcaça dos suínos e reduzindo o impacto ambiental dos dejetos produzidos.

$\mathrm{O}$ fato de o triptofano ser importante no sistema imunológico e ter nos seus metabólitos os principais produtos envolvidos na regulação do consumo e do estresse (Henry et al., 1992) torna fundamental o estabelecimento do nível correto deste aminoácido nas rações.

Neste contexto, este trabalho foi realizado para avaliar os efeitos de níveis de triptofano digestível nas rações sobre o desempenho e as características de carcaça de suínos machos castrados, selecionados geneticamente para deposição de carne na carcaça, dos 60 aos $95 \mathrm{~kg}$.

\section{Material e Métodos}

O experimento foi conduzido na Granja de Suínos da Fazenda Experimental Vale do Piranga, de propriedade da EPAMIG, localizada no município de Oratórios-MG.

Foram utilizados 70 suínos machos castrados, híbridos comerciais de alto potencial genético para deposição de carne na carcaça, com peso inicial de $60,00 \pm 1,34 \mathrm{~kg}$, distribuídos em delineamento experimental de blocos ao acaso, com cinco tratamentos $(0,128 ; 0,136 ; 0,144 ; 0,152 \mathrm{e}$ $0,160 \%$ de triptofano digestível, correspondentes às relações de triptofano digestível:lisina digestível de 16,17,18, 19 e 20\%, respectivamente), sete repetições e dois animais por unidade experimental. Na distribuição dos animais dentro de cada bloco, adotou-se como critério o peso inicial dos animais.
Os animais foram alojados em baias providas de comedouros semi-automáticos e bebedouros automáticos tipo chupeta, em um galpão de alvenaria com piso de concreto e cobertura de telhas de amianto.

As rações experimentais (Tabela 1), isoenergéticas e isoaminoacídicas, foram suplementadas com minerais e vitaminas para atender tsodas as exigências nutricionais dos animais, conforme descrito por Rostagno et al. (2000), com exceção do triptofano.

Em todas as rações, foi verificada a relação aminoacídica entre lisina e os demais aminoácidos essenciais, a fim de garantir as relações ideais entre os aminoácidos. Na avaliação das relações aminoacídicas das rações, foram utilizadas aquelas preconizadas por Rostagno et al. (2000) com base na proteína ideal, para suínos em fase de terminação.

Os animais receberam as rações experimentais e água à vontade. As rações e as sobras foram pesadas periodicamente, enquanto os animais foram pesados no início e no final do período experimental para avaliação do ganho de peso, do consumo de ração e da conversão alimentar.

Ao final do período experimental, quando atingiram $95,00 \pm 0,97 \mathrm{~kg}$, os animais foram submetidos a jejum alimentar por 18 horas e encaminhados para abate em frigorífico comercial localizado no município de Ponte Nova-MG. Os animais foram abatidos por atordoamento elétrico e sangramento e, em seguida, foram depilados com lançachamas e eviscerados. As carcaças foram avaliadas quanto ao rendimento de carne e à espessura de toucinho, por meio de aparelho de tipificação de carcaça (GP-4 Henessy - Nova Zelândia - Solft Didai).

Tabela 1 - Composição centesimal das dietas experimentais

Table 1 - Ingredient and calculated compositions of the experimental diets

\begin{tabular}{|c|c|c|c|c|c|}
\hline \multirow[t]{2}{*}{$\begin{array}{l}\text { Ingrediente }(\%) \\
\text { Ingredient }\end{array}$} & \multicolumn{5}{|c|}{$\begin{array}{c}\text { Nível de triptofano digestível (\%) } \\
\text { Digestible tryptophan level }\end{array}$} \\
\hline & 0,128 & 0,136 & 0,144 & 0,152 & 0,160 \\
\hline Milho (Corn) & 77,992 & 77,992 & 77,992 & 77,992 & 77,992 \\
\hline Farelo de soja (Soybean meal) & 13,900 & 13,900 & 13,900 & 13,900 & 13,900 \\
\hline Farelo de glúten milho 60 (Corn gluten meal 60 ) & 5,000 & 5,000 & 5,000 & 5,000 & 5,000 \\
\hline L-lisina HCL (HCL L-lysine) & 0,338 & 0,338 & 0,338 & 0,338 & 0,338 \\
\hline L-treonina (L-threonine) & 0,060 & 0,060 & 0,060 & 0,060 & 0,060 \\
\hline L-triptofano(L-thryptophan) & - & 0,009 & 0,018 & 0,026 & 0,035 \\
\hline DL-metionina (DL-methionine) & 0,032 & 0,032 & 0,032 & 0,032 & 0,032 \\
\hline Ac. glutâmico(Glutamic acid) & 0,100 & 0,087 & 0,073 & 0,060 & 0,047 \\
\hline Amido (Starch) & 0,100 & 0,104 & 0,109 & 0,114 & 0,118 \\
\hline Fosfato bicálcico (Dicalcium phosphate) & 1,210 & 1,210 & 1,210 & 1,210 & 1,210 \\
\hline Calcário (Limestone) & 0,737 & 0,737 & 0,737 & 0,737 & 0,737 \\
\hline Premix vitamínico ${ }^{1}$ (Vitamin mix) & 0,100 & 0,100 & 0,100 & 0,100 & 0,100 \\
\hline Premix mineral $^{2}$ (Mineral mix) & 0,100 & 0,100 & 0,100 & 0,100 & 0,100 \\
\hline Sal (Salt) & 0,321 & 0,321 & 0,321 & 0,321 & 0,321 \\
\hline BHT & 0,010 & 0,010 & 0,010 & 0,010 & 0,010 \\
\hline Total & 100,00 & 100,00 & 100,00 & 100,00 & 100,00 \\
\hline
\end{tabular}


Tabela 2 - Desempenho e características de carcaça de suínos machos castrados de alto potencial genético para deposição de carne, dos 60 aos $95 \mathrm{~kg}$ recebendo diferentes níveis de triptofano digestível na ração

Table 2 - Performance and carcass characteristics of barrows with high genetic potential for lean deposition from 60 to $95 \mathrm{~kg}$ according to the dietary digestible tryptophan levels

\begin{tabular}{|c|c|c|c|c|c|c|}
\hline & \multicolumn{5}{|c|}{$\begin{array}{c}\text { Nível de triptofano digestível (\%) } \\
\text { Digestible tryptophan level }\end{array}$} & \multirow[t]{2}{*}{$\mathrm{CV}(\%)$} \\
\hline & 0,128 & 0,136 & 0,144 & 0,152 & 0,160 & \\
\hline Ganho de peso diário (g) (Daily weight gain) & 1.162 & 1.145 & 1.185 & 1.161 & 1.178 & 6,40 \\
\hline Conversão alimentar (Feed:gain ratio) & 2,50 & 2,50 & 2,58 & 2,52 & 2,60 & 4,30 \\
\hline Consumo de triptofano diário $(\mathrm{g})^{1}$ (Daily tryptophan intake) & 3,71 & 3,89 & 4,41 & 4,44 & 4,88 & 6,40 \\
\hline
\end{tabular}

${ }^{1}$ Efeito linear $(\mathrm{P}<0,05)$ (Linear effect).

Assim, os dados obtidos não confirmaram o relato de Henry \& Séve (1993) de que o nível de triptofano na ração deve ser superior a $4 \%$ da soma dos AAN para evitar uma possível redução do consumo voluntário de ração pelos suínos.

Os níveis de triptofano digestível não influenciaram ( $P>0,05)$ o GPD, evidenciando que o nível de $0,128 \%$ de triptofano digestível, correspondente a uma menor relação com a lisina digestível, de $16 \%$, foi suficiente para atender à exigência dos animais para ganho de peso.

Este resultado corrobora o obtido por Fremaut \& Deschrijver (1990), que, avaliando níveis de triptofano para suínos na fase de terminação, em que a relação triptofano:lisina variou de 18 a 24\%, não observaram efeito dos tratamentos sobre o ganho de peso dos animais. Em contrapartida, Henry et al. (1992, 1996) e Henry (1995) constataram efeito negativo do baixo nível de triptofano sobre o ganho de peso de suínos machos castrados e de fêmeas na fase de terminação.

Mais recentemente, Eder et al. (2003) e Guzik et al. (2005) verificaram que o ganho de peso de suínos na fase de terminação foi significativamente influenciado pelos níveis de triptofano da ração e que as melhores respostas de ganho ocorreram nos níveis de 0,146 e $0,096 \%$, respectivamente, de triptofano digestível, que corresponderam a uma mesma relação de $18 \%$ com a lisina digestível. Os resultados destes últimos autores evidenciaram que a exigência de triptofano digestível pode variar em função do nível de lisina digestível utilizado nas rações experimentais.

A conversão alimentar dos animais não foi influenciada $(\mathrm{P}>0,05)$ pelos tratamentos. Ficou evidenciado com este resultado que o menor nível de triptofano digestível avaliado neste estudo $(0,128 \%)$, correspondente à relação de $16 \%$ com a lisina digestível, atendeu à exigência dos animais e não comprometeu a eficiência de utilização da ração para ganho de peso.

De forma semelhante, Fremaut \& Deschrijver (1990), avaliando níveis de triptofano total de 0,150 a $0,202 \%$ para suínos na fase de terminação, não constataram efeito dos tratamentos sobre a CA dos animais. O resultado obtido também está coerente com os dados de Eder et al. (2003), que, estudando níveis de triptofano digestível entre 0,071 e $0,171 \%$ e entre 0,049 e $0,129 \%$, em que as relações com a lisina digestível variaram de 8,9 a $21 \%$ e de 8,7 a $23 \%$, respectivamente, em rações para suínos de 50 a $80 \mathrm{~kg}$ e de 80 a $115 \mathrm{~kg}$, não observaram variação significativa na CA dos animais a partir dos níveis de 0,121 e $0,089 \%$ de triptofano digestível, que corresponderam à relação de $15 \%$ com a lisina digestível para ambas as faixas de peso.

Por outro lado, Guzik et al. (2005) verificaram que a CA dos suínos em terminação foi influenciada pelos níveis de triptofano digestível, com a melhor resposta obtida no nível de $0,109 \%$, que correspondeu a $21 \%$ da lisina digestível.

Apesar das variações de resultados entre os trabalhos, o nível de triptofano digestível $(0,128 \%)$ que proporcionou a melhor resposta de CA neste estudo foi similar ao de $0,129 \%$, preconizado por Rostagno et al. (2005) para suínos machos castrados dos 70 aos $100 \mathrm{~kg}$, e superior aos de 0,12 e $0,10 \%$, recomendados pelo NRC (1998) para suínos de 50 a $80 \mathrm{~kg}$ e de 80 a $120 \mathrm{~kg}$, respectivamente.

Observou-se efeito $(\mathrm{P}<0,05)$ dos tratamentos sobre o CTD, que aumentou de forma linear segundo a equação $\hat{\mathrm{Y}}=-0,912+35,970 \mathrm{X}\left(\mathrm{r}^{2}=0,95\right)$, como resultado do consumo de ração, que não variou entre os tratamentos.

Como os melhores resultados de desempenho (GPD e CA) foram obtidos no nível de $0,128 \%$, pode-se inferir que o consumo diário de 3,71 g de triptofano digestível atendeu à demanda dos animais. Este valor foi semelhante aos de 3,71 e 3,77 g de triptofano digestível encontrados por Eder et al. (2003) para melhor resposta de desempenho de suínos de 50 a $80 \mathrm{~kg}$ e de 80 a $115 \mathrm{~kg}$, respectivamente, e ao de 3,80 g, calculado por Guzik et al. (2005) para suínos dos 74,6 aos $104,5 \mathrm{~kg}$.

Não foi observada influência $(\mathrm{P}>0,05)$ dos níveis de triptofano digestível da ração sobre as características de 
carcaça avaliadas. Os resultados de rendimento de carne na carcaça encontrados estiveram de acordo com os padrões de respostas de ganho de peso e conversão alimentar verificados entre os tratamentos neste estudo.

De forma similar, Fremaut \& Deschrijver (1990) e Henry et al. (1992) não notaram variação significativa na espessura de toucinho e na porcentagem de carne na carcaça de suínos em terminação com a elevação do nível de triptofano da ração.

Por outro lado, Guzik et al. (2005) verificaram aumento linear na espessura de toucinho dos suínos em terminação, como resultado da elevação da concentração de triptofano digestível da ração entre 0,06 e $0,14 \%$, embora a porcentagem de carne não tenha alterado significativamente entre os tratamentos.

Considerando os resultados obtidos, pode-se inferir q ue o nível de $0,128 \%$ de triptofano digestível, correspondente a uma relação de $16 \%$ com lisina digestível, foi suficiente para atender às exigências de suínos machos castrados dos 60 aos $95 \mathrm{~kg}$ para melhor desempenho e rendimento de carne e menor espessura de toucinho. Esta relação se assemelha à encontrada por Kendall et al. (2003), que obtiveram as melhores respostas em suínos machos castrados dos 91 aos $124 \mathrm{~kg}$ no nível de triptofano digestível correspondente a uma relação com a lisina digestível de $16,5 \%$.

Entretanto, esse resultado diverge dos obtidos por Hahn et al. (1995) e Guzik et al. (2005), que observaram melhores respostas de desempenho e de características de carcaça de suínos em terminação em níveis de triptofano digestível cujas relações com a lisina digestível foram de 20 a $22 \%$. Difere também das relações de 19 e $20 \%$ entre esses aminoácidos, propostas, respectivamente, por Hahn \& Backer (1995) e Rostagno et al. (2005) com base no conceito de proteína ideal para suínos em terminação.

Essas divergências de resultados entre os trabalhos podem estar relacionadas, entre outros fatores, a diferenças no desafio imunológico dos animais utilizados, como sugerido por Le Floc'h et al. (2004) e Melchior et al. (2004), que afirmaram que as exigências de alguns aminoácidos, entre eles o triptofano, seriam aumentadas durante a estimulação do sistema imune dos suínos.

\section{Conclusões}

O nível de $0,128 \%$ de triptofano digestível, correspondente a uma relação triptofano:lisina digestíveis de $16 \%$, proporcionou os melhores resultados de desempenho e de características de carcaça de suínos machos castrados de alto potencial genético para deposição de carne na carcaça dos 60 aos $95 \mathrm{~kg}$.

\section{Literatura Citada}

EDER, K.; NONN, H.; KLUGE, H. et al. Tryptophan requirement of growing pigs at various body weights. Journal of Animal Physiology and Animal Nutrition, v.87, p.336-346, 2003.

FREMAUT, D.; SCHRIJVER, D.R. Tryptophan supplementation of diets for growing-finishing pigs. Revue de I'Agriculture, v.43, p.761-768, 1990

GUZIK, A.C.; SHELTON, J.L.; SOUTHERN, L.L. et al. The tryptophan requirement of growing and finishing barrows. Journal of Animal Science, v.83, p.1303-1311, 2005.

HAHN, J.D.; BAKER, D. Optimum ratio to lysine of threonine, tryptophan, and sulfur amino acids for finishing swine.Journal of Animal Science, v.73, p.482-489, 1995.

HAHN, J.D.; BIEHL, R.R.; BAKER, D. Ideal digestible lysine level for early and late finishing swine. Journal of Animal Science, v.73, p.773-784, 1995.

HENRY, Y. Effects of dietary tryptophan deficiency in finishing pigs, according to age or weight at slaughter or live weight gain. Livestock Production Science, v.73, p.63-76, 1995.

HENRY, Y.; SÈVE, B. Prise en compte de l'excês alimentaire d'acides aminés neutres pour la correction de l'équilibre do tryptophan, par rapport a la lysine, chez le porc en croissance. Journal Recherches Porcines, v.25, p.247-253, 1993.

HENRY, Y.; SÈVE, B.; COLLÉAUX, Y. et al. Interactive effects of dietary levels of tryptophan and protein on voluntary feed intake an growth performance in pigs, in relation to plasma free amino acids and hypothalamic serotonin. Journal of Animal Science, v.70, p.1873-1887, 1992.

HENRY, Y.; SÈVE, B.; MOUNIER, A. et al. Growth performance and brain neurotransmitters in pigs as affected by tryptophan, protein, and sex. Journal of Animal Science, v.74, p.27002710, 1996.

KENDALL, D.C.; KERR, B.J.; BOYD, R.D. et al. Determination of the TID tryptophan:lysine ratio for $90 \mathrm{~kg}$ barrows.Journal of Animal Science, v.81, p.139, 2003 (suppl. 1).

LE FLOC'H, N.; MELCHIOR, D.; OBLED, C. Modifications of protein and amino acid metabolism during inflammation and immune system activation. Livestock Production Science, v.87, p.37-45, 2004.

MELCHIOR, D.; SÉVE, B.; LE FLOC'H, N. Chronic lung inflammation affects plasma amino acid concentrations in pigs. Journal of Animal Science, v.82, p.1991-1099, 2004.

NATIONAL RESEARCH COUNCIL - NRC. Nutritional requirements of swine. 10.ed. Washington, D.C.: National Academic Science, 1998. 186p.

ROSSONI, M.C.; DONZELE, J.L.; SILVA, F.C.O. et al. Avaliação de diferentes relações triptofano:lisina digestíveis em rações para suínos machos castrados dos 60 aos $95 \mathrm{~kg}$. In: CONGRESSO BRASILEIRO DE VETERINÁRIOS ESPECIALISTAS EM SUÍNOS, 11., 2003, Goiás. Anais... Goiânia: Associação Brasileira de Veterinários Especialistas em Suínos, 2003. p.35-54.

ROSTAGNO, H.S.; ALBINO, L.F.T.; DONZELE, J.L. et al.Tabelas brasileiras para aves e suínos: composição de alimentos e exigências nutricionais. 1.ed. Viçosa, MG: Universidade Federal de Viçosa, 2000. 141p.

ROSTAGNO, H.S.; ALBINO, L.F.T.; DONZELE, J.L. et al.Tabelas brasileiras para aves e suínos: composição de alimentos e exigências nutricionais. 2.ed. Viçosa, MG: Universidade Federal de Viçosa, 2005. 189p.

UNIVERSIDADE FEDERAL DE VIÇOSA - UFV. Sistema de análises estatísticas e genéticas - SAEG . Versão 8.0. Viçosa, MG: 2000. 142p.

Recebido: 29/09/05 Aprovado: 26/06/06 